\title{
The effect on compliance of a health education leaflet in colorectal cancer screening in general practice in central England
}

\author{
Andrew R Hart, T Lynne Barone, Simon P Gay, Alastair Inglis, Lynne Griffin, \\ Carole A Tallon, John F Mayberry
}

\begin{abstract}
Objective - To raise compliance in a general practice based colorectal cancer screening programme by the use of a simple health educational leaflet.

Design - A randomised controlled trial of the leaflet's effect on completion of faecal occult blood tests. The leaflet explained the high frequency of colorectal cancer, the principles of screening. and addressed reasons for non-compliance.

Setting - The British town of Market Harborough where most of the population are registered with a single practice.

Participants - These comprised 1571 residents aged 61 to 70 years registered with the practice. Residents were invited to receive a free faecal occult blood test in a colorectal cancer screening programme. Half the population were randomly assigned to receive the educational leaflet about screening.

Results - Compliance in test and control groups, positive rate of stool testing, and pathology detected were measured. Compliance was higher in men who received the leaflet in those aged 61 to 65 years $(36 \%$ v $\left.27 \%, \chi^{2}=4.0, p<0.05\right)$ and in men aged 66 to 70 years $\left(39 \%\right.$ v $\left.23 \%, \chi^{2}=9.7, p<0.01\right)$. In women, use of the leaflet did not affect compliance in those aged either 61 to 65 years $\left(38 \% \vee 36 \%, \chi^{2}=0.1\right.$, NS) or 66 to 70 years $\left(31 \%\right.$ v $\left.31 \%, \chi^{2}=0.0, \mathrm{NS}\right)$. The positive rate of stool testing in patients observing the required dietary restrictions was $1.6 \%$. A significant lesion was detected in $1.4 \%$ of people tested ( 2 carcinomas and 5 patients with adenomatous polyps).

Conclusions - Health education leaflets addressing reasons for non-compliance significantly increased compliance in men and should be used in screening programmes. Reasons for the lack of success of the leaflet in women should be investigated and other interventions for raising compliance should be developed.
\end{abstract}

( $\mathcal{F}$ Epidemiol Community Health 1997;51:187-191)

Colorectal cancer is the second commonest cause of cancer death with 17300 deaths each year in England and Wales ${ }^{1}$ and 57000 in the United States. ${ }^{2}$ Large trials of screening with faecal occult blood tests showed more early Dukes's A tumours and premalignant ad- enomatous polyps in those screened than in controls. $^{3-7}$ Currently, only one study has reported mortality data; this showed that stool testing reduced colorectal cancer mortality by $33 \% .{ }^{4}$ A high compliance rate is essential for any screening programme to be successful. In any future national screening programme for colorectal cancer, invitations will come from patients' general practitioners. Unfortunately, in studies from British general practices, acceptance is often less than $50 \%,,^{8-11}$ and new methods for increasing uptake must be developed. One approach is to enclose an educational booklet with the test invitation. This would explain the rationale of screening and address reasons for non-compliance. Currently, the role of these health educational leaflets is unclear, ${ }^{12-14}$ and, importantly, reasons for noncompliance are not addressed and the leaflets are unpublished. ${ }^{1213}$

This study assessed the effect of an educational leaflet on compliance in a randomised controlled trial of faecal occult blood testing in primary care. The study population comprised residents, aged 61 to 70 years, of Market Harborough, a mixed suburban and rural area of Britain. Here a large group practice of 10 doctors serves most of the community. The educational leaflet explained the high frequency of colorectal cancer, screening, and faecal occult blood testing and addressed reasons for noncompliance. These reasons had been identified by detailed interviews of 82 subjects who had failed to comply with a previous screening programme offered to this community. ${ }^{115}$ To ensure the booklet was readable, provided sufficient information, and raised the recipient's intention to participate it was piloted on 100 subjects who accompanied patients to a hospital clinic. Subjects were asked to comment on the leaflet's explanations of screening and the screening tests. Most commented that these were either "very well" or "well" explained.

\section{Methods}

An invitation to receive a free faecal occult blood test was sent to 1571 residents of Market Harborough aged 61 to 70 years registered with the practice (appendix 1). The letter was sent on practice notepaper and signed by the senior partner. Half of the subjects were randomly allocated to receive a leaflet about colorectal cancer screening (appendix 2). In households with two eligible members, both received the same intervention (leaflet or no leaflet), and to 
eliminate bias only the first member alphabetically was included in the analysis. The leaflet explained the high frequency of colorectal cancer and adenomatous polyps, the beneficial effects of polypectomy and the asymptomatic nature of the lesions. Screening was defined and faecal occult blood testing explained. Finally, in an attempt to raise compliance, the reasons for non-compliance were addressed. The leaflet did not mention the frequency with which screening should be undertaken as this was a "one-off" research study to assess the effect of the educational intervention. The screening programme was not advertised in the local press or on radio to avoid contaminating any effect of the booklet. A prepaid envelope was included with which to return the request for the stool testing kit.

Subjects who accepted screening were sent a free faecal occult blood test (Haemoccult) which included instructions on how to use it. Tests were completed over three days and returned to Leicester General Hospital for testing. Initially no dietary restrictions were imposed but subjects were asked to refrain from taking vitamin $\mathrm{C}$ preparations which can cause false negative results. Subjects with positive tests were asked to repeat them while observing dietary restrictions - particularly while avoiding red meat as this decreases the number of false positives by $60 \% .^{16}$ Subjects with repeat positive tests were informed and their general practitioner referred them for colonoscopy.

All subjects who had a negative faecal occult blood test were informed of the result, but told to contact their general practitioner if they had or developed symptoms. Individuals who had an initial positive but a repeat negative test were sent a third test four months later.

The number of subjects completing kits was recorded in relation to age, sex ,and whether they received the leaflet or not. Differences between these groups were tested for statistical significance using a $\chi^{2}$ test. To determine whether previous participation influenced participation in the second study, the number of people who completed kits twice was expressed as a percentage of total participation in the second study. The readability, human interest, and positivity of the material were calculated using Flesch readability and interest scores. ${ }^{1718}$ The Flesch formula measures reading level on a scale of 0 to 100 . It calculates the average number of syllables per 100 words and the average number of words per sentence. The higher the score the more readable the material. Human interest is evaluated by counting the number of personal words and sentences which include personal words such as first, second, and third person pronouns. Again a score from 0 to 100 is allocated. ${ }^{17}$ Finally, an assessment of the positivity or negativity of reading material can be calculated by counting the number of negative words such as "can't", "won't", etc.

\section{Results}

THE UPTAKE OF SCREENING

Compliance with screening - that is, the number of subjects who completed faecal occult
Table 1 Compliance with faecal occult blood testing in men and women randomised to receive or not to receive an explanatory leaflet in Market Harborough, Leicestershire

\begin{tabular}{lll}
\hline & Leaflet & No leaflet \\
\hline Men & & \\
$61-65 y$ & $36 \%(72 / 199)$ & $27 \%(52 / 194)$ \\
$66-70 y$ & $39 \%(71 / 182)$ & $23 \%(39 / 166)$ \\
Women & & \\
$61-65 \mathrm{y}$ & $38 \%(79 / 209)$ & $36 \%(67 / 186)$ \\
$66-70 \mathrm{y}$ & $31 \%(66 / 216)$ & $31 \%(67 / 219)$ \\
\hline
\end{tabular}

blood kits - was 33\% (513/1571, table 1). The booklet raised compliance in men aged both 61 to 65 years $\left(36 \%\right.$ v $\left.27 \%, \chi^{2}=4.0, p<0.05\right)$ and in males aged 66 to 70 years (39\% v $23 \%$, $\left.\chi^{2}=9.7, p<0.01\right)$. In women, the addition of the booklet to the screening invitation did not affect compliance in either those aged 61 to 65 years $\left(38 \% \mathrm{v} 36 \%, \chi^{2}=0.1, \mathrm{NS}\right)$ or those aged 66 to 70 years $\left(31 \% \vee 31 \%, \chi^{2}=0.0, N S\right)$.

Compliance rates in men and women who received the booklet were similar $(38 \%$ v $34 \%$, $\chi^{2}=1.0$, NS. Significantly more women who did not receive the booklet complied than men who did not receive the booklet (33\% v $25 \%$, $\chi^{2}=5.6, p<0.02$ ).

An estimate was made as to whether compliance in the first study influenced participation in the second study. The number of people who completed kits twice was calculated and expressed as a percentage of total kit completion in the second study. All those resident in Market Harborough in the first study and still in the town during the second would have been offered screening twice (first study population aged 50 to 70 years, second study population 61 to 70 years). Of the total number of men who participated in the second programme, $75 \%$ had previously complied, and the figure for women was $83 \%$.

Nineteen subjects had initial positive faecal occult blood tests (3.7\% of those tested) but only eight were again positive on repeat testing $(1.6 \%)$. The abnormalities detected at screening were carcinoma (Dukes's A and B) in two, adenomatous lesions in five, and inflammatory polyps in one person.

\section{READABILITY OF THE LEAFLET}

The Flesch reading score was 73.7 (range 0 to 100 ), which is the reading level of a 12 year old. The leaflet had a positivity score of 94 (range 0 to 100) which is classed as "optimistic", and a human interest score of 12 (range 0 to 100) which is rated "impersonal".

\section{Discussion}

The main finding of this study was that a health education leaflet could significantly increase compliance in men but not women. The leaflet increased the total number of men who completed faecal occult blood tests by $52 \%$ (from $25 \%$ to $38 \%$ ). The positive effect of a leaflet in men is encouraging, especially as the intervention is cheap and can be included with screening invitations. Based on population figures from the 1991 British census, ${ }^{19}$ in a national screening programme such a leaflet 
would recruit an extra 72000 men leading to the detection of 500 asymptomatic tumours. This positive effect is more likely because of the leaflet's explanations of why screening tests should be completed and the way it addresses reasons for non-compliance.

There are several possible explanations for why the leaflet worked in men but not in women. Breast and cervical screening programmes may make women more aware of the concepts of asymptomatic illness and the benefits of early detection. Conversely, men are less conscious of screening as there are no national programmes in Britain for detection of cancer in men and so they are more likely to be influenced by the benefits explained in the leaflet. A second possibility is that many women have had unpleasant experiences during mammography ${ }^{20}$ and smear testing ${ }^{21-23}$ These include painful investigations and embarrassment and loss of dignity when attending screening centres. Consequently, they may have been unconvinced by our leaflet which portrayed the investigations which follow a positive stool test as acceptable. Future research into compliance with colorectal cancer screening should explore the effect of unpleasant experiences in one screening programme on participation in others. Health education material sent to men and women may also have to differ in emphasis. In men the principles of screening should be highlighted and in women reservations about the screening test overcome. Alternatively, other forms of health education may be more effective in women. More women than men aged 40 to 70 years accepted faecal occult blood testing when it was offered at routine consultations, ${ }^{24}$ and a more personal approach from family doctors may be required. Women are familiar with such an approach in cervical cancer screening where general practitioners encourage smear testing and are involved in the procedure.

Although the leaflet increased compliance, overall uptake was disappointing at $33 \%$. A possible reason was that there was no advance publicity in the local press or radio. Advance publicity and prior knowledge of a colorectal cancer screening programme can themselves raise compliance by $10 \%$ and direct interview of potential participants by $15 \% .{ }^{25}$ Another reason for the low overall acceptance may be that this was the second programme in two and a half years. Several residents wrote stating they had participated earlier and thought further testing unnecessary. However, we feel that most people appreciated screening is a continuous process as $75 \%$ of men and $83 \%$ of women who participated in the second study had complied with the first. Although the leaflet was effective in men, other interventions to raise compliance are clearly needed as overall compliance was low.

Compliance rates in men and women who received the leaflet were similar, although in most programmes acceptance is lower in men. ${ }^{8112426}$ In those who did not receive the leaflet, acceptance was lower in men than women. The major effect of the leaflet was to raise male acceptance of screening to a level comparable with that in women.

This is the first British study in which an educational leaflet about colorectal cancer screening has been assessed for readability, in which reasons for non-compliance were addressed, and which was piloted in a preliminary study. Readability was assessed with the Flesch reading score. ${ }^{1718}$ Such objective scales are invaluable tools for writing and simplifying educational material and they correlate with understanding and retention of information. ${ }^{18}$ The high readability score of our leaflet may have contributed to its effect on men.

Other studies in British general practice have given conflicting results on the value of health education in encouraging participation in colorectal cancer screening programmes. A community study in Nottinghamshire found an educational leaflet actually reduced compliance from $55 \%$ to $46 \% .{ }^{14}$ Mailing the leaflet two weeks before the invitation also had a detrimental effect. There are several possible reasons for the ineffectiveness of their leaflet. Firstly, its purpose was not explained, although the fact that the illness often presents late, at a time when treatment is ineffective, was mentioned. Such an approach is unlikely to interest healthy people in the benefits of screening and causes fear in others. Furthermore, symptoms were discussed, which is confusing in a leaflet about screening, and reasons for non-compliance were not addressed. In another English study, ${ }^{13}$ compliance with faecal occult blood testing was similar in those receiving educational material and controls. The leaflet was not published, although the authors stated it was about "bowel diseases and screening for bowel cancer and polyps". Neither readability nor a preliminary study were reported.

This study assessed the leaflet's effect on several methods of recruitment including simply mailing a kit, offering it at routine consultation, and giving patients specific appointment times to come and collect the test. Of these three methods, the offer of screening at a routine consultation was most effective. However, within each group, the educational booklet had no significant impact, possibly because reasons for non-compliance were not addressed.

This study also emphasised the importance of doctors informing patients of their results and asking them to seek medical advice if symptomatic. One lady who complained of constipation for several months had positive tests initially but negative ones after she had been observing advised dietary restrictions. On receipt of her test result letter she contacted the screening unit and was investigated with a barium enema. This showed a stricture in the caecum, which at laparotomy was seen to be of a benign fibrous nature.

This study showed educational leaflets which are simple, positive, and address reasons for non-participation can increase compliance. Such leaflets are cheap to print and their development and use in future general practice screening programmes should be encouraged. 
Appendix 1

STANDARD INVITATION LETTER

Market Harborough Medical Centre,

67 Coventry Road,

Market Harborough,

Leicestershire.

Dear

As your family doctor I would be very pleased if you would participate in a new and simple screening test to make sure that the lining of your bowel is healthy. I am offering this test to patients of your age, who like yourself, have no particular bowel symptoms.

In the whole of Leicestershire there are over 300 new cases of bowel cancer each year. Detection in the early stages greatly increases the chances of a complete cure.

These tests can detect small amounts of blood in the stool that would normally go unnoticed. Often the cause if not serious, but if may indicate the earliest stage of bowel cancer when treatment can result in a complete cure.

If you would like to receive one of these kits with an instruction leaflet, please complete and return the slip below in the enclosed envelope. This screening programme is similar to one offered 2 years ago to people living in the area. If you require any further information please telephone Leicester 490490, extension 4352.

Yours sincerely,

MF Biggin \& Partners

\section{Full NAME}

Address

I would/would not like to receive a free stool kit (Please delete)

\section{Appendix 2}

THE SCREENING BOOKLET

How I can help myself avoid the second commonest cancer in Britain?

This leaflet is about how bowel cancer may be found before symptoms appear. This is called screening. This leaflet answers questions about screening.

How common is bowel cancer?

Bowel cancer is the second commonest cancer in Britain affecting 28000 people each year. About one in every 26 people will have the illness at some time. Many more people have polyps in the bowel. A polyp is a harmless growth tag, arising from the bowel wall. About 1 in 10 polyps turn into cancers after many years. Removal of these polyps should prevent cancer. Can bowel cancer be present before causing symptoms?

YES. Bowel cancer may be present for many months before giving any symptoms. Polyps or pre-cancers rarely give symptoms. What is screening?

Screening is where people have tests to find cancer before it gives symptoms. Bowel cancers found by screening are easier to cure. Screening also finds bowel polyps. Removing these polyps should prevent cancer.

What are the screening tests for bowel cancer?

The simplest screening test is done at home. This home test consists of three small cardboard slides. Tiny samples of motion are smeared on the slides. The slides are then tested at the hospital for invisible traces of blood from cancers and polyps.

How easy is the home test to do?

The test is very easy. It may not sound nice, but it can be done quickly and cleanly. A leaflet in the home test explains how to do the slides. A few minutes spent doing this test may save your life.

Will I need more tests after the home test?

Only one in every hundred people will need further tests.

The recommended test uses a flexible camera to look at the bowel. This is done as an outpatient. Through the camera cancers may be found and polyps removed. Medicines are given to relax the bowel and make you sleepy. This makes the test easier.

Can the home test help me if I feel well and have no bowel symptoms?

YES. You may still have an early cancer or polyp which has not yet given symptoms. Early cancers are easier to treat and removal of any polyps may prevent cancer developing.

Will other illnesses interfere with the home test?

$N O$. If you are unwell or have another illness you may still do a home test after talking with your family doctor.

What if I don't have time to do the home test?

The test only takes several minutes but may save your life by finding cancer early.

1 Office of Population Censuses and Surveys. Mortality stat istics 1985. Series DH2.12. London: HMSO, 1987. istics 1985. Series DH2.12. London: HMSO, 1987. 1993. CA Cancer f Clin 1993;43:7-26.

$C A$ Cancer 7 Clin 1993;43:7-26.
Thomas WM, Hardcastle JD. An update on the Nottingham Thomas WM, Hardcastle JD. An update on the Nottingham
trial of faecal occult blood screening for colorectal carcinoma. In: Miller AB, Chamberlain J, Day NE, Hakama M, Prorok PC eds. Cancer screening. Cambridge: Cambridge University Press, 1991:106-115.

4 Mandel JS, Bond JH, Church TR, et al. Reducing mortality from colorectal cancer by screening for fecal occult blood. $N$ Eng $\mathcal{F}$ Med 1993:328:1365-71.

5 Kronborg $\mathrm{O}$, Fenger $\mathrm{C}$, Olsen J. Interim report on a randomised trial of screening for colorectal cancer with Haemoccult II. In: Miller AB, Chamberlain J, Day NE, Hakam M, Prorok PC, eds. Cancer screening. Cambridge: Cam bridge University Press, 1991:116-25.

6 Kewenter J, Asztely M, Engaras B, Haglind E, Svanvik J, Ant Ahren C. A randomised trial of faecal and rescreening of 51325 subjects. In: Miller AB, Cham berlain J, Day NE, Hakama M, Prorok PC, eds. Cancer screening. Cambridge: Cambridge University Press, 1991 : 116-25.

7 Winnawer SJ, Schottenfeld D, Flehinger BJ. Colorectal cancer screening. I Nat Cancer Inst 1991;83:243-53.

8 Farrands PA, Griffiths RL, Brotton DC. The Frome Ex periment-Value of screening for colorectal cancer. Lance 1981;i:1231-32.

9 Million R, Howarth J, Turnberg E, Turnberg LA. Faecal occult blood testing for colorectal cancer in general practice. The Practitioner 1982;226:659-63.

10 Lallemand RC, Vakil PA, Pearson P, Box V. Screening for asymptomatic bowel cancer in general practice. $B M$ 1984;228:331-33.

11 Hart AR, Gay SP, Donnelly A, et al. Screening for colorecta cancer in Market Harborough, UK: a community based prorame Eur 7 Gastronterl Hepatol 1994;6:519-22.

12 programme. Eur 7 . occult blood Acreening for colorectal cancer in the general occult blood screening for colorectal cancer in the general population.

13 Nichols S, Koch E, Lallemand RC et al. Randomised trial of compliance with screening for colorectal cancer. $B M \mathcal{F}$ 1986;293:107-10. 
14 Pye G, Chamberlain JO, Moss SM, Hardcastle JD. A comparison of methods of increasing compliance within general practitioner based screening project for colorectal cancer and the effect on practitioner workload. 7 Epidemio Community Health 1988;42:66-71.

15 Hynam KA, Hart AR, Gay SP, Inglis A, Wicks ACB, Mayberry JF. Screening for colorectal cancer: reasons for refusal of faecal occult blood testing in general practice in England $\mathcal{F}$ Epidemiol Community Health 1995;49: 84-86.

16 Thomas WM, Pye G, Hardcastle JD, Chamberlain J, Charnley RM. Role of dietary restriction in Haemoccult screening for colorectal cancer. $\mathrm{Br} f$ Surg 1989;76: 976-78.

17 Flesch R. A new readability yardstick. $\mathcal{F}$ Appl Psychol 1948 32:221-23.

18 Klare GR. A second look at the validity of readability formulas. Fournal of Reading Behaviour 1976;8: 129-52.

19 The 1991 Census. Persons aged 60 and over, Great Britain. London: OPCS, 1993.
20 Maclean U, Sinfield D, Klein S, Harnden B. Women who decline breast cancer screening. $\mathcal{f}$ Epidemiol Community dealth 1984:38:278-83.

21 Elkind A K, Haran D, Eardley A, Spencer B. Computermanaged cervical cytology screening: a pilot study of nonattenders. Public Health 1978;101:253-66.

22 Nathoo V. Investigation of non-responders at a cervical cancer screening clinic in Manchester. BMF 1988:296: 1041-42.

23 King J. Women's attitudes towards cervical smear. Update 1987:34:160-68.

24 Hobbs FD, Cherry RC, Fielding JWL, Pike L, Holder R. Acceptability of opportunistic screening for occult gastrointestinal blood loss. BMF 1992;304:483-86.

25 Hardcastle JD, Farrands PA, Balfour TW, Chamberlain J Amar SS, Sheldon MG. Controlled trial of faecal occult blood testing in the detection of colorectal cancer. Lancet 1983;ii: $1-4$.

26 Hardcastle JD, Thomas WM, Chamberlain J, et al. Randomised controlled trial of faecal occult blood screening for colorectal cancer. Results for first 107349 subjects. Lancet 1989;i:1160-64. 